\title{
Variação espacial das concentrações de cádmio e manganês em solo ocupado por aterro sanitário
}

\author{
Pedro Daniel da Cunha Kemerich', Carlos Eduardo Balestrin Flores², Willian Fernando de Borba ${ }^{3}$, \\ Bruno Acosta Flores ${ }^{4}$, Leônidas Luiz Descovi Vicatto Filho ${ }^{5}$, Guilherme Barros ${ }^{6}$, \\ Ademir Eloi Gerhardt ${ }^{7}$, Alexandre Couto Rodrigues ${ }^{8}$
}

\author{
'Doutorando em Engenharia Ambiental da UFSC. Coordenador do Curso de Engenharia Ambiental da Universidade Federal de Santa \\ Maria/CESNORS - Frederico Westphalen, RS - Brasil \\ ${ }^{2467}$ Acadêmico do curso de Engenharia Ambiental da UFSM - Santa Maria, RS - Brasil \\ ${ }^{3}$ Acadêmico do curso de Engenharia Ambiental da Universidade Federal de Santa Maria - Santa Maria, RS - Brasil \\ ${ }^{5}$ Doutorando em Geografia pela UFSC, pesquisador no Laboratória de Análise Ambiental - UFSC - Florianópolis, SC - Brasil \\ ${ }^{8}$ Pós-Doutorado em Ecofisiologia Vegetal pelo Institut National de la Recherche Agronomique INRA - França. Professor Adjunto da Uni- \\ versidade Federal de Santa Maria - Santa Maria, RS - Brasil
}

\begin{abstract}
Resumo
Os aterros sanitários configuram-se, como uma maneira correta e segura de disposição final dos resíduos sólidos, porém exigem sérios estudos para sua escolha. Sendo assim o presente estudo teve por objetivo determinar o potencial de contaminação química do solo por Cádmio e Manganês em decorrência da ocupação por aterro sanitário. No presente estudo, ocorreu a tradagem para coleta das amostras sendo realizados em função da topografia existente no aterro e do fluxo preferencial de água superficial, considerando-se 10 pontos de coleta denominados P1 a P10. As análises foram realizadas pelo equipamento Shimadzu Energy Dispersion Fluorescence X-ray Spectrometer Rany, Serie EDX-720. O manganês apresentou altas concentrações em todos os pontos estudados, sendo a maior concentração no P4 a 200 cm (11.576,46 mg kg-1), já a menor concentração foi apresentada no P7 a 300 cm (516.237 mg kg-1), devido a concentração elevada deste elemento, ele se torna prejudicial ao solo e a vegetação existente no local. Já para Cádmio as maiores concentrações ocorreram no P7 em 100 cm de profundidade (57238 mg kg-1) e P9 em $300 \mathrm{~cm}$ de profundidade (36319 mg kg-1). Com base nisso, foi possível concluir que as maiores concentrações de Cádmio ocorreram nas profundidades variando de 100 a $200 \mathrm{~cm}$, demonstrando que ocorreu aumento da concentração com a profundidade. Já a vulnerabilidade, foi classificada como baixa, assim apresentando-se pouco vulnerável a contaminação do aquífero. Palavras-chave: Contaminação do Solo; Metais; Resíduos sólidos.
\end{abstract}

\begin{abstract}
Landfills are configured as a correct and safe way of disposal of solid waste, but require serious study for your choice. Therefore this study aimed to determine the potential for contamination of soil by cadmium and manganese as a result of the occupation by landfill. In the present study, there was a borehole to collect the samples being made according to the existing topography at the site and preferential flow of surface water, considering 10 collection points called P1 to P10. Analyses were performed by Shimadzu Energy Dispersion X-ray Fluorescence Spectrometer Rany, Serie EDX-720. Manganese showed high levels at all points studied with P4 at the highest concentration to $200 \mathrm{~cm}$ (11576.46 mg kg-1) has the lowest concentration shown in P7 was $300 \mathrm{~cm}$ (516 $237 \mathrm{mg} \mathrm{kg}-1)$ due high concentration of this element, it becomes harmful to the soil and vegetation at the site. As for Cadmium higher concentrations occurred at P7 at $100 \mathrm{~cm} \mathrm{depth}(57238 \mathrm{mg}$ $\mathrm{kg}-1)$ and P9 at $300 \mathrm{~cm}$ depth (36319 mg kg-1). Based on this, it was concluded that the highest concentrations of cadmium occurred at depths ranging from 100 to $200 \mathrm{~cm}$, showing that there was an increased concentration with depth. Already vulnerability has been classified as low, thus presenting little susceptible to contamination of groundwater.
\end{abstract}

Key-words: Contamination of Soil; Metals; Solid waste. 


\section{INTRODUÇÃO}

Com o aumento populacional, o consumo desenfreado e as necessidades do ser humano, o meio ambiente torna-se cada vez mais vulnerável em relação às formas de contaminação e poluição que a sociedade moderna dita, tendo em vista os aterros sanitários uma das melhores soluções para minimizar ou até mesmo atenuar um dos grandes problemas da sociedade.

$\mathrm{O}$ aterro sanitário é um aprimoramento de uma das técnicas mais antigas utilizadas pelo homem para descarte de seus resíduos, que é o aterramento. Modernamente, é uma obra de engenharia que tem como objetivo acomodar no solo resíduo no menor espaço prático possível, causando o menor dano possível ao meio ambiente ou à saúde pública (CETESB, 2013).

Uma das grandes preocupações ambientais está relacionada aos resíduos sólidos gerados pela sociedade moderna e consumista. Com a intensificação do processo industrial, aliada ao crescimento da população e à consequente demanda por bens de consumo, o homem tem produzido quantidades significativas de resíduos sólidos, que acabam sendo constituídos de uma mistura muito complexa e de natureza diversa, cujos principais constituintes são: material orgânico, papel, vidro, plástico e metais (LEITE et al., 2004)

A pesquisa nacional de saneamento básico do ano de 2000 revela que das 228.413 toneladas de lixo geradas diariamente no Brasil, 21\% tem como destinação lixões a céu aberto ou áreas alagadas, $37 \%$ são levadas a aterros controlados, $36 \%$ vão para aterros sanitários, 2,8\% são utilizados na compostagem, $0,9 \%$ vão para usinas de triagem e $0,5 \%$ são incinerados (IBGE, 2000).

Os aterros, embora importantes, apresentam algumas limitações como o tempo de vida razoavelmente curto e a grande dificuldade na obtenção de locais adequados para sua implementação nas proximidades dos centros urbanos, sem que se trate de locais de recarga de aquífero ou inadequado para outros serviços (MUÑOZ, 2002).

De uma forma geral, as áreas receptoras desses resíduos não são o ponto final para muitas das substâncias existentes nos materiais depositados e para as que ainda irão se formar por meio das reações químicas e biológicas. Prova disso, é que áreas muitas vezes distantes dos aterros sanitários, aterros controlados ou lixões são negativamente impactados, tendo seus usos comprometidos (Santos \& Medeiros, 2011).

A disposição de resíduos sem os devidos cuidados pode gerar a proliferação de agentes patogênicos, acarretar na poluição do solo, ar e de recursos hídricos através da migração dos elementos constituintes do chorume e de gases produzidos através do processo de degradação da matéria orgânica desses depósitos (Tartari, 2005).

O lixiviado pode agregar em sua composição matéria orgânica dissolvida, componentes orgânicos antrópicos e metais tóxicos como o Manganês e o Cádmio (Barbosa et al., 2000).

Tanto os resíduos gerados na área industrial e urbana, quanto os produtos utilizados na agricultura, tem como destino final o seu descarte no solo. Esta situação pode ser problemática ao longo dos anos, pois tais produtos podem apresentar em suas composições elementos tóxicos como o cádmio (Loganathan et al., 1997).

Mais de $90 \%$ do cádmio na superfície ambiental é proveniente de fontes antropogênicas, incluindo fertilizante fosfatado de rochas usadas como insumos agrícolas ou subprodutos com finalidade corretiva ou nutricional na agricultura, cinzas da queima dos combustíveis fósseis, bem como os resíduos da fabricação do cimento e trabalhos metalúrgicos, lixos da cidade, lodo de esgoto e depósitos atmosféricos (Pan et al., 2010; Silva et al., 2010).

O cádmio é um metal tóxico e que vem sendo preocupante principalmente a partir de 1960 quando foi descrita uma doença óssea dolorosa semelhante à osteoporose, após contaminação ambiental ocorrida no Japão, proveniente da exploração de uma mina de zinco e chumbo junto a um rio, cuja população consumiu durante 30 anos de sua água e o arroz ali produzido propiciou o desenvolvimento desta doença. O cádmio pode acarretar 31 comprometimentos à saúde, principalmente nos ossos e rins, inclusive em população não exposta durante o trabalho e mesmo em doses baixas de exposição tanto em adultos quanto em crianças. Seu acúmulo ocorre em maior quantidade nos órgãos do que nos músculos ou gorduras, e em maior quantidade nos rins do que no fígado ( $\mathrm{Pan}$ et al., 2010; Fontaine et al., 2008).

Entre os metais pesados contaminantes podemos citar o manganês $(\mathrm{Mn})$, que é um elemento essencial aos animais, seres humanos e vegetais superiores, sendo o elemento mais abundante do solo depois do ferro (Pelozato, 2008). Porém, se absorvidos em quantidades superiores ao necessário podem se tornar um contaminante em potencial, causando problemas no metabolismo (Nascentes et al., 2009).

O principal uso do manganês é na indústria 
metalúrgica, compondo ligas metálicas a base de Mn e na fabricação de pilhas, que podem ser fontes de contaminação do solo em aterros sanitários.

Óxidos de manganês possuem uma química muito complexa em função de alguns fatores: (a) vários estados de oxidação, que envolvem $\mathrm{Mn}^{2+}$, $\mathrm{Mn}^{3+} \mathrm{e} \mathrm{Mn}^{4+}$; (b) formação de óxidos hidratados não estequiométricos com metais em estados de valência mistos; (c) óxidos em estados cristalinos e pseudocristalinos; (d) formação de coprecipitados, precipitados e superestruturas com óxidos de ferro (Lindsay, 1979).

A solubilidade do manganês no solo é afetada por $\mathrm{pH}$, potencial redox e complexação (Lindsay, 1979). Esta solubilidade aumenta com o aumento das condições de acidez (baixo pH) e do potencial redox. Nestas condições, as concentrações de $\mathrm{Mn}^{2+}$ podem tornar-se fitotóxicas (Bohn et al., 1979; Atta et al., 1996).

Com base no tema exposto, o trabalho teve como objetivo determinar o potencial de contaminação química do solo por Cádmio e Manganês em decorrência da ocupação por aterro sanitário no Município de Seberi-RS.

\section{MATERIAL E METODOS}

\section{I Caracterização da área de estudo}

O município de Seberi está situado no noroeste do estado do Rio Grande do Sul, Brasil, em uma latitude $27^{\circ} 28^{\prime} 4^{\prime \prime} \mathrm{S}$ e longitude $53^{\circ}$ 24' 09", com altitude de $546 \mathrm{~m}$ do nível do mar, abrangendo uma área de $301 \mathrm{~km}^{2}$ e com população de 11098 habitantes, sendo o mesmo pertencente à bacia hidrográfica do Rio Uruguai com clima subtropical úmido (IBGE, 2009). O Aterro está localizado na BR $386 \mathrm{~km} \mathrm{43,} \mathrm{Distrito} \mathrm{de} \mathrm{Osvaldo}$ Cruz, cidade de Seberi - RS. É um consórcio entre 30 municípios abrangendo uma área total 7,77 ha, com abrangência de $4.88360 \mathrm{~km}^{2}$, atende $162 \mathrm{mil}$ habitantes, recebem cerca de 1200 toneladas de resíduos sólidos urbanos mensalmente.

\subsection{Localização dos pontos de amostragem e coleta de amostras}

A tradagem para coleta das amostras foi realizada em função da topografia existente no aterro e do fluxo preferencial de água superficial, determinado com o auxílio do software Surfer

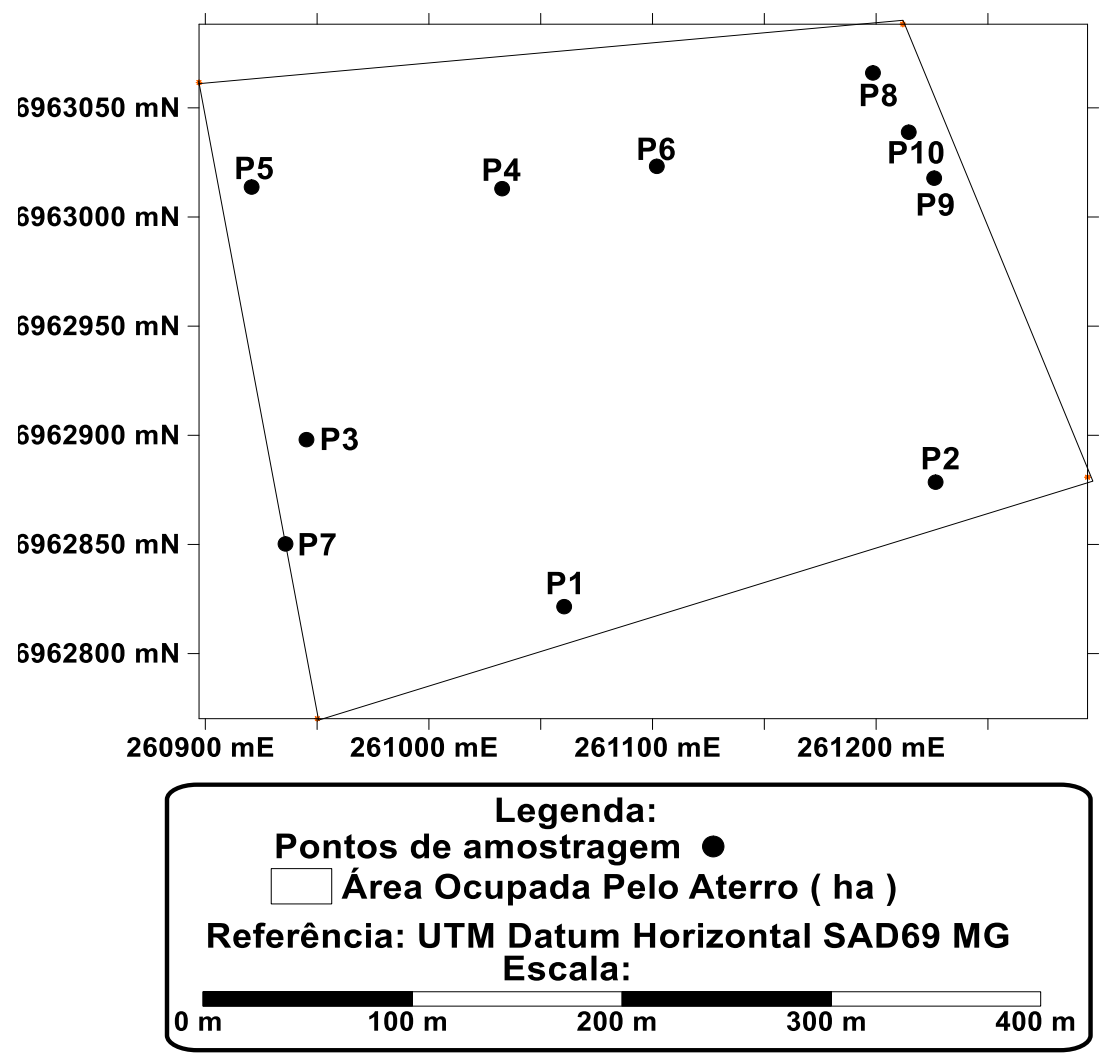

Figura 1. Localização dos pontos de amostragem com as linhas de fluxo, Seberi, 2012. 

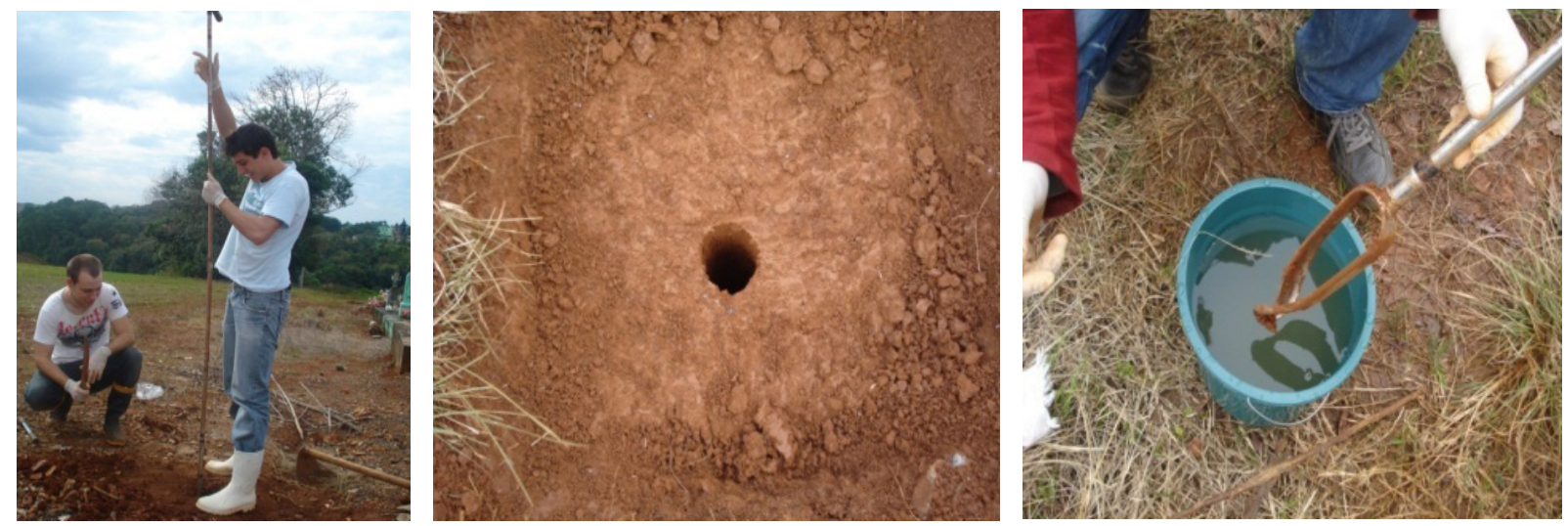

Figura 2. Tradagem efetuada no aterro sanitário em Seberi - RS, utilizando trado manual Sonda terra com 3 metros de haste (a), local de tradagem (b) e limpeza do trado em água destilada (c), Seberi - RS, 2012.

9.0 da Golden Software, utilizando-se o método de interpolação matemática Krigagem (Landim e Sturato, 2002), conforme ilustra (figura 1). Foram considerados 10 pontos de coleta denominados $\mathrm{P} 1$, P2, P3, P4, P5, P6, P7, P8, P9 e P10, sendo que P1 o ponto de maior cota topográfica com $545,42 \mathrm{~m}$ e o P10 encontra-se no ponto de menor elevação, sendo considerado o ponto controle.

Para a coleta das amostras foi utilizado, um trado manual Sonda Terra de $3 \mathrm{~m}$ de comprimento (Figura 2a). Cada amostra coletada foi armazenada em sacos plásticos e recebeu identificação correspondendo à localização do ponto de amostragem e a profundidade da coleta. Nos 10 pontos analisados foram coletadas amostras a cada $50 \mathrm{~cm}$ de profundidade, iniciando-se com a amostra superficial em $0 \mathrm{~cm}$ a $300 \mathrm{~cm}$, totalizado 7 amostras por ponto (Figura 2b). Para evitar alterações nos resultados o trado era lavado com água destilada, conforme a figura 2c.

\subsection{Preparo de amostras e determinação dos elementos quìmicos}

Foram pesadas $20 \mathrm{~g}$ de solo e encaminhadas para a secagem em estufa de esterilização e secagem, utilizando vidraria básica de laboratório (Becker $50 \mathrm{~mL}$ ) para sua deposição. O processo de secagem ocorreu à temperatura de $105^{\circ} \mathrm{C}$ por duas horas, do mesmo modo utilizado por Kemerich et al., (2012).

Após a secagem da amostra, as análises foram realizadas utilizando-se um Espectrômetro de Fluorescência de Raios-X por Energia Dispersiva (EDXRF), do modelo Shimadzu EDX-720. As seguintes condições de operação do equipamento foram selecionadas: tensão do tubo de $15 \mathrm{keV}(\mathrm{Na}$ a Sc) e $50 \mathrm{keV}$ ( $\mathrm{Ti}$ a U) com corrente no tubo de 184 $\mu \mathrm{A}$ e $25 \mu \mathrm{A}$ respectivamente, colimador de $10 \mathrm{~mm}$, tempo morto do detector de $40 \%$ e $39 \%$, sob vácuo e detector de $\mathrm{Si}(\mathrm{Li})$ refrigerado com nitrogênio líquido, (Pataca et al., 2005), com tempo real de integração de 200 segundos, tempo este diferente do usado por Pataca et al. (2005) e Wastowski et al. (2010) que utilizaram $300 \mathrm{~s}$. Wastowski et al. (2010) sugere para corrigir os efeitos de absorção e calibrar as linhas espectrais dos elementos analisados, utilizou-se o padrão A-750. Este padrão de calibração utilizado o qual foi fornecido junto com o Modelo EDX-720, e trata-se de uma liga metálica composta por Alumínio (Al), Estanho (Sn), Magnésio (Mg), Ferro (Fe) e Cobre ( $\mathrm{Cu}$ ). Desta maneira é possível determinar-se a composição do material analisado.

O método analítico usado é denominado método dos Parâmetros Fundamentais (FP), este método permite a obtenção da curva de sensibilidade do equipamento para cada elemento de interesse, quando uma amostra de composição química conhecida é submetida a parâmetros instrumentais bem definidos (Bona et al., 2007; Wastowski et al., 2010). A curva de sensibilidade do equipamento relaciona a intensidade fluorescente teórica calculada e a medida para cada elemento (Bona et al., 2007). Wastowski et al. (2010) dizem que para análises de rotina em massa, se as amostras de calibração estão ausentes, o método (FP) pode fornecer resultados relativamente precisos e quantitativos (Han et al., 2006).

\subsection{Determinação da vulnerabilidade god}

A metodologia "GOD" (G - groundwater hydraulic confinement; $\mathrm{O}$ - overlaying strata; D - depth to groundwater table), elaborada por Foster et al., (2006), correspondente a: G - Grau de confimanto hidráulico da água subterrânea/ aquífero; $\mathrm{O}$ - Ocorrência de extratos de cobertura; 


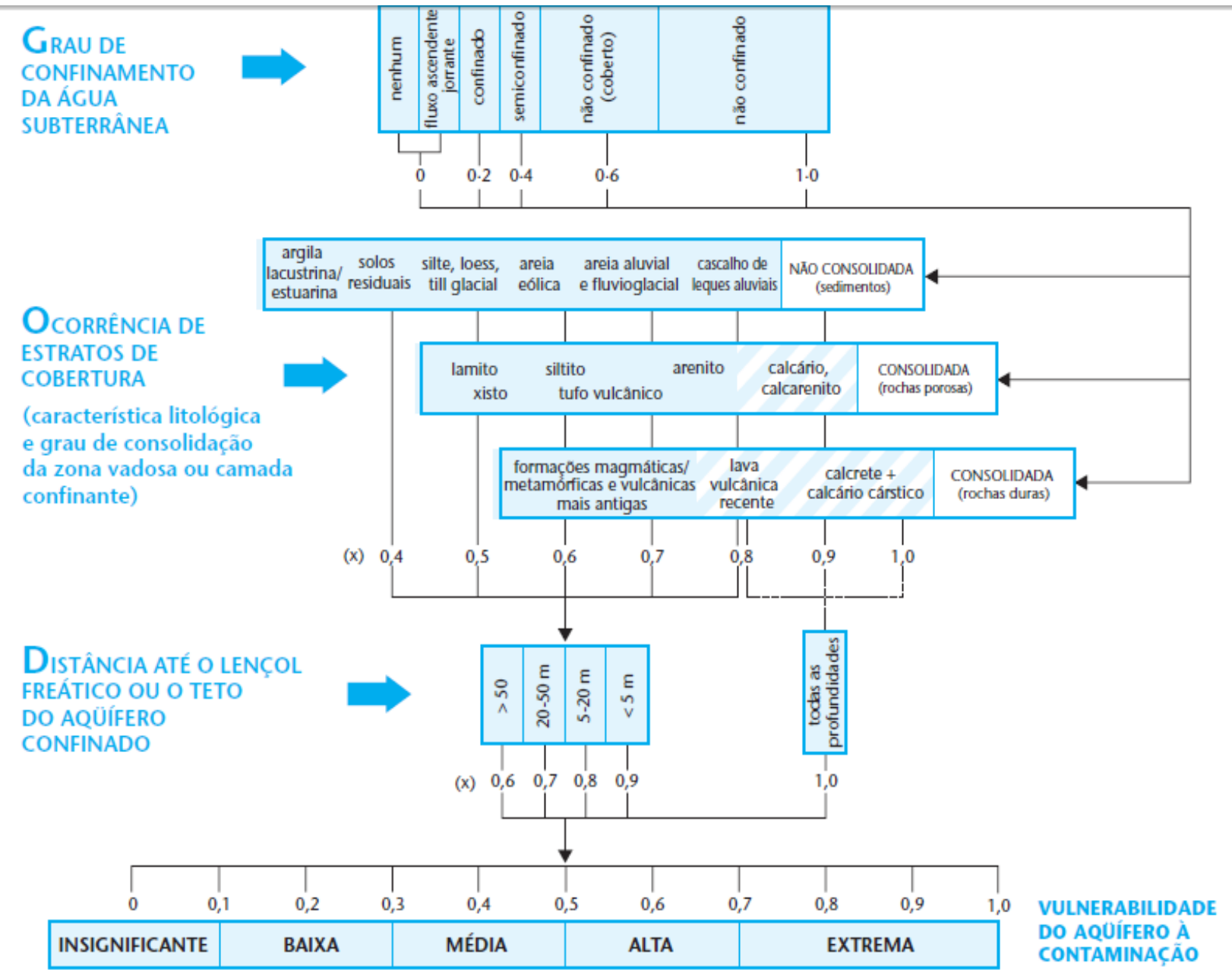

Figura 3. Sistema GOD para avaliação da vulnerabilidade do aquífero Foster et al. (2006).

D - Distância/Profundidade até o lençol freático, foi a metodologia utilizada para a definição dos índices de vulnerabilidade das diferentes áreas (Kemerich et al., 2013). O índice de vulnerabilidade "GOD" seguiu as etapas ilustradas na figura 3.

Inicialmente identificou-se o grau de confinamento hidráulico do aquífero, atribuindo-lhe um índice entre 0,0 a 1,0 . Foram considerados confinados obtendo nota 0,2 , e aqueles semi-confinados nota 0,4. Especificaram-se as características do substrato que recobre a zona saturada do aquífero em termos de: (a) grau de consolidação e (b) litologia, assinalando um índice a este parâmetro em uma escala de 0,4 a 1,0 .

Considerou-se distância ou profundidade ao nível da água (em aquíferos não confinados) ou profundidade do teto da camada do primeiro aquífero confinado, assinalando um índice a este parâmetro em uma escala de 0,6 a 1,0.

$O$ índice final integrado da avaliação de vulnerabilidade do aquífero à contaminação "GOD" é o produto dos valores obtidos para cada um dos parâmetros, variando de 0,0 (insignificante) até 1,0 (extrema).

\section{RESULTADOS E DISCUSSÃO}

\section{I Cádmio}

Segundo Gonçalves et al. (1999) o valor de $0,5 \mathrm{mg} \mathrm{kg}^{-1}$ de cádmio serve como referência de solo não contaminado. A Resolução CONAMA n ${ }^{\circ}$ 420 de 28 de dezembro de 2009 estabelece valores de cádmio para prevenção em solos brasileiros com $1,3 \mathrm{mg} \mathrm{kg}^{-1}$, mas consta que o limite de investigação para águas subterrâneas são de $5 \mu \mathrm{g} \mathrm{L}^{-1}$, sendo padrões de potabilidade de substâncias químicas que representam risco à saúde.

Dependendo dos atributos físicos, químicos e mineralógicos do solo, eles podem reter o $\mathrm{Cd}$ em formas não biodisponíveis, diminuindo assim os riscos de contaminação do ambiente. 

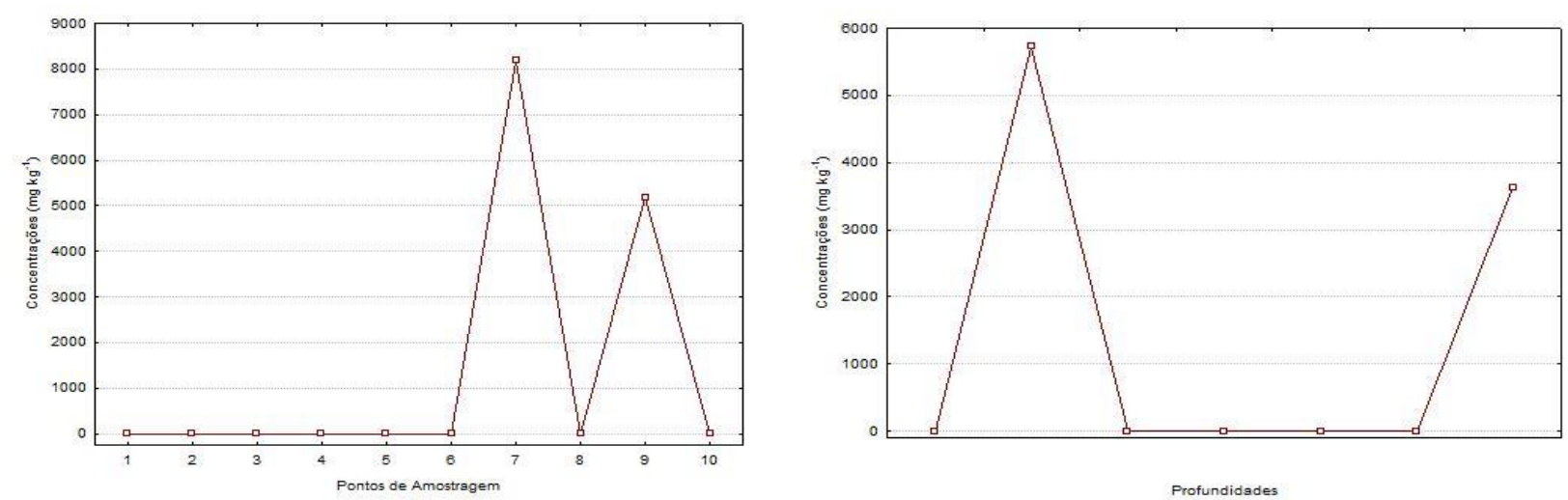

Profundidades

Figura 4. Variação da concentração de cádmio nos 10 pontos de amostragem (a) e nas 7 diferentes profundidades (b) no aterro sanitário, Seberi-RS, 2012.

Os solos, dependendo de seus atributos físicos, químicos e mineralógicos podem adsorver (reter) o $\mathrm{Cd}$ em formas não biodisponíveis, diminuindo assim os riscos de contaminação do ambiente. A persistência e a mobilidade do Cd em solos são determinadas por reações de adsorção, dessorção e precipitação dos elementos no solo. Os atributos que influenciam diretamente na capacidade de retenção do cádmio em solos são, os teores de matéria orgânica, argila, óxidos, capacidade de troca de cátions (CTC), $\mathrm{pH}$, força iônica da solução, área superficial específica (ASE) e a mineralogia (King., 1988).

$\mathrm{Na}$ área de estudo, nas profundidades de 0 a $300 \mathrm{~cm}$, as maiores concentrações ocorreram no P7 em $100 \mathrm{~cm}\left(57238 \mathrm{mg} \mathrm{kg}^{-1}\right)$ e P9 em $300 \mathrm{~cm}$ $\left(36319 \mathrm{mg} \mathrm{kg}^{-1}\right)$. Metais pesados em excesso podem causar muitas doenças e sérios problemas fisiológicos, já que são acumulativos no corpo humano. Os resíduos contendo cádmio possuem um alto poder de contaminação e, com facilidade, atingem os lençóis freáticos ou mesmo reservatórios e rios, que são as fontes de abastecimento de água das cidades (Jimenez et al., 2004). A figura 4 ilustra a variação da concentração de cádmio total nos 10 pontos de amostragem (a) e nas 7 diferentes profundidades (b).

Como pode ser observado na figura 4 , as maiores concentrações de cádmio foram observadas no P7, já a profundidade de $50 \mathrm{~cm}$ apresentou os maiores valores para esse elemento.

Carvalho et al.,(2010) ao estudar os metais pesados cujos solos principais foram o Latossolo Amarelo e o Argissolo Amarelo, verificou valores de cádmio $\left(0,5 \mathrm{mg} \mathrm{kg}^{-1}\right)$.

A média de valores para cádmio obtidos por Lazarini (2011) nos bairros Soledade e Robalo, Aracaju-SE foram de $2,85 \mathrm{mg} \mathrm{kg}^{-1}$, valores em muito superior aos encontrados por Carvalho et. al., (2010).

\subsection{Manganês}

O elemento manganês, apresentou a maior concentração no $\mathrm{P} 4$ a $200 \mathrm{~cm}$ de profundidade (11576,46 mg kg-1), já a menor concentração foi apresentada no P7 a $300 \mathrm{~cm}\left(516,237 \mathrm{mg} \mathrm{kg}^{-1}\right), \mathrm{Na}$

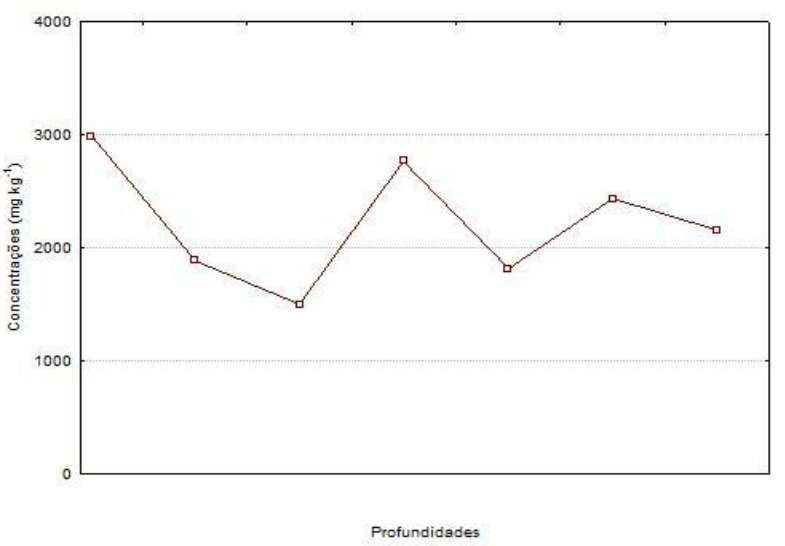

Figura 5. Variação da concentração de Manganês nos 10 pontos de amostragem (a) e nas 7 diferentes profundidades (b) no aterro sanitário, Seberi-RS, 2012. 
profundidade de $0 \mathrm{~cm}$, o P5 apresentou a maior concentração $\left(8645,978 \mathrm{mg} \mathrm{kg}^{-1}\right)$. Em $50 \mathrm{~cm}$, o maior valor foi de $5.366,72 \mathrm{mg} \mathrm{kg}^{-1}$ (P3) e o menor foi de $835,49 \mathrm{mg} \mathrm{kg}^{-1}$ (P7), já em $100 \mathrm{~cm}$ a maior concentração esteve presente no P3 (3.753,16 mg $\left.\mathrm{kg}^{-1}\right)$ e a menor no P2 $\left(688,64 \mathrm{mg} \mathrm{kg}^{-1}\right)$.

Nos solos brasileiros, esse elemento ocorre na faixa de $10 \mathrm{a} 4.000 \mathrm{mg} \mathrm{kg}^{-1}$ de manganês total ou 0,1 a $100 \mathrm{mg} \mathrm{kg}^{-1}$ de manganês solúvel em acetato de amônio (MALAVOLTA, 1980).

Segundo Silva (2012) a prática de manejo do solo e aplicação de defensivos agrícolas, causa contaminação ao solo por cobre, já a adubação orgânica proporciona muitos benefícios ao solo, porem aumenta o teor de metais como o manganês.

$\mathrm{Na}$ área de estudo, com profundidade de $200 \mathrm{~cm}$, a maior concentração esteve presente no ponto $\mathrm{P} 4\left(11.576,46 \mathrm{mg} \mathrm{kg}^{-1}\right)$, já a menor ocorreu a $0 \mathrm{~cm}$ com 757,14 $\mathrm{mg} \mathrm{kg}^{-1}$. Em 250 e $300 \mathrm{~cm}$, o P3 apresentou as maiores concentrações $(8800,30$ mg kg-1 e 7733,80 $\mathrm{mg} \mathrm{kg}^{-1}$ ), já a $0 \mathrm{~cm}$ foram encontrados os menores valores sendo no P9 $(688,64 \mathrm{mg}$ $\left.\mathrm{kg}^{-1}\right)$ e o P7 $\left(516,24 \mathrm{mg} \mathrm{kg}^{-1}\right)$.

Segundo Nascimento (2006), as principais formas de ocorrência de manganês no solo são aquelas em que ele se encontra participando da estrutura dos minerais e como complexos associados à matéria orgânica.

Agourakis (2006) afirma que o manganês, apesar de ser essenciais aos seres vivos em baixas concentrações, é particularmente tóxico quando em concentrações elevadas. A figura 5 ilustra a variação da concentração de Manganês total nos 10 pontos de amostragem (a) e nas 7 diferentes profundidades (b).

Como pode ser observado na figura 4 , as maiores concentrações de Manganês foram observadas no $\mathrm{P} 8$, já a profundidade de $0 \mathrm{~cm}$ apresentou os maiores valores para esse elemento.

\section{3 Índice de vulnerabilidade god}

Com base na vulnerabilidade GOD (Foster et al., 2006), a área de estudo apresentou baixa vulnerabilidade de contaminação do aquífero, conforme ilustra a figura 6 .

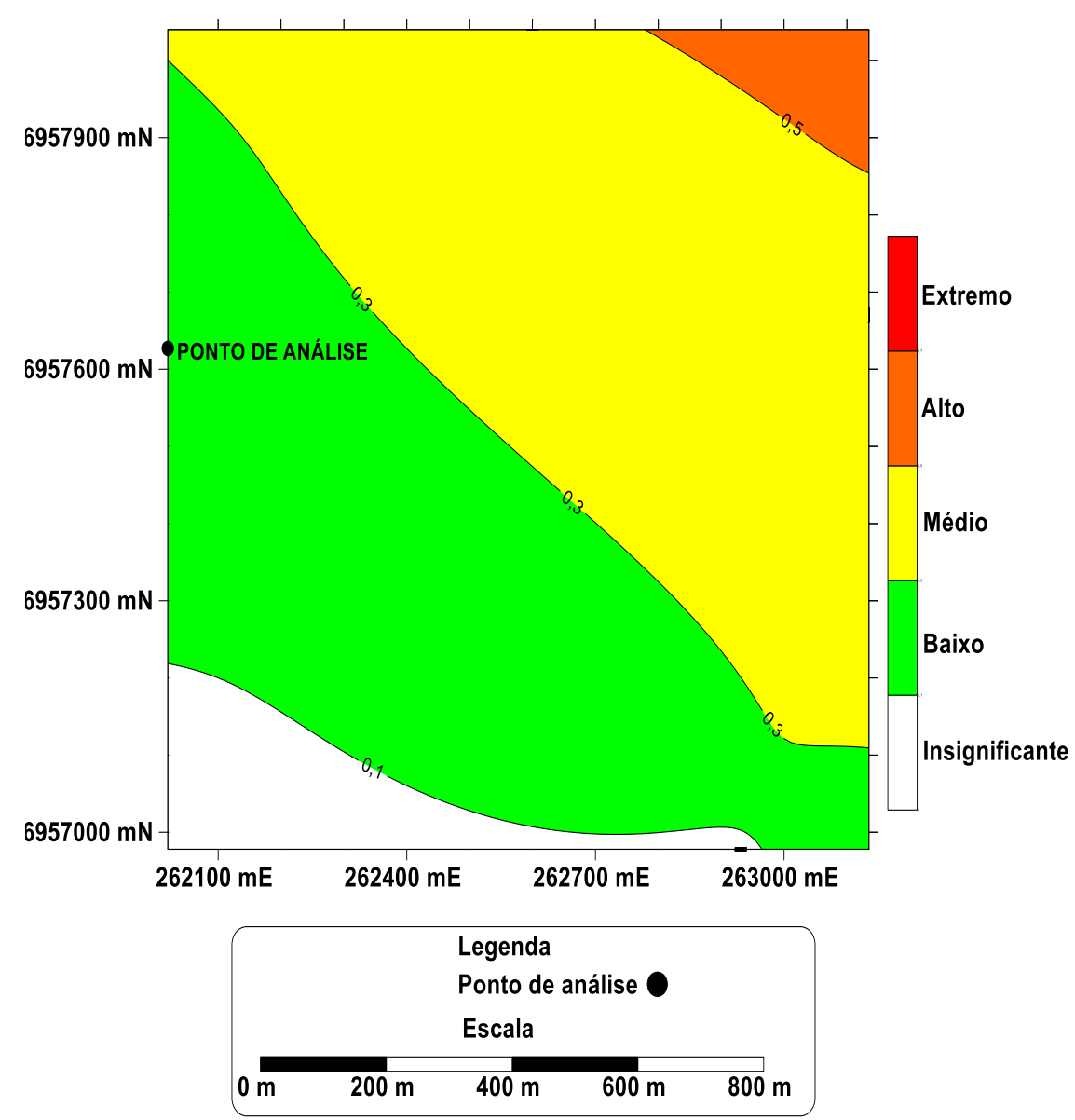

Figura 6 - Vulnerabilidade GOD (Foster et al., 2006) na área de estudo, Seberi, 2012. 
Com base nisso, a área apresenta baixo potencial a contaminação, pois possui um aquífero profundo, confinado. Diversos autores utilizam tal metodologia para a determinação da vulnerabilidade, onde destacam-se os trabalhos desenvolvidos por Barboza et al. (2007), Kemerich et al. (2013) e Oliveira et al. (2004), onde as áreas estudadas apresentaram vulnerabilidades variando de Insignificante a extrema.

\section{CONCLUSÃO}

A técnica de Espectrometria Fluorescência de Raios - X por energia dispersiva demonstrou ser rápida e eficiente para quantificação de metais em solos ocupados por cemitério e com possível utilização para o monitoramento ambiental.

Pela análise do solo por EDXRF foi possível determinar as concentrações de cádmio e manganês. O manganês apresentou altas concentrações em todos os pontos estudados. Devido à concentração elevada deste elemento, ele se torna prejudicial ao solo e a vegetação existente no local. Já para Cádmio as maiores concentrações ocorreram no P7 em $100 \mathrm{~cm}\left(57238 \mathrm{mg} \mathrm{kg}^{-1}\right)$ e P9 em $300 \mathrm{~cm}$ (36319 $\mathrm{mg} \mathrm{kg}^{-1}$ ). Nos demais pontos e profundidades as concentrações foram abaixo do limite de detecção, o que nos leva a concluir de uma forma concreta que o grande número de testes realizado não interfere na qualidade ou estrutura do solo. A vulnerabilidade na área foi classificada como baixa, com um solo de lençol freático profundo e aquífero confinado.

\section{REFERÊNCIAS}

AGOURAK, D. C.; CAMARGO, I. M. C.; COTRIM, M. B.; FLUES, M. Comportamento de zinco e manganês de pilhas alcalinas em uma coluna de solo. Quím. Nova vol. 29 n. 5 São Paulo Sept./ Oct. 2006.

ATTA, S.Kh.; MOHAMME, S.A.; CLEEMPUT, 0 . Van; ZAYED, A. Transformations of iron and manganese under controlled Eh, Eh-pH conditions and addition of organic matter. Soil Technology, 9: 223-237, 1996.

BARBOSA, R. M.; OTERO, O. M. F; ARGÔLO, J. L.; QUEIROZ, A. F. S.; SANTOS, V. C. S.; OLIVEIRA, O. M. C. O chorume dos depósitos de lixo: composição, evolução, diluição, extensão, processos, poluição e atenuação. Tecbahia, Salvador, ano
14 , n. 1, p. 212-224, 2000.

BARBOZA, A. E. C.; ROCHA, S. F.; GUIMARAES, W. D. Estudo preliminar da vulnerabilidade do aquífero livre localizado na região de Ponta da Fruta, Vila Velha ES. In: XIII Simpósio Brasileiro de Sensoriamento Remoto, 2007, Florianópolis. Anais XIII Simpósio Brasileiro de Sensoriamento Remoto, Florianópolis, Brasil. SÃO JOSÉ DOS CAMPOS: INPE, 2007. v. 21. p. 3279-3286.

BOHN, H.L.; MCNEAL, B.L.; O'CONNOR, G. A. Soil chemistry. New York, Wiley-Interscience, 1979. $325 \mathrm{p}$.

BONA, I. A. T.; SARKIS, J. E. S.; SALVADOR, V. L. R.; SOARES, A. L. R.; KLAMT, S. L. Análise arqueométrica de cerâmica Tupiguarani da região central do Estado do Rio Grande do Sul, Brasil, usanndo fluorescência de raios X por dispersão de energia (EDXRF). Revista Química Nova, São Paulo, n. 30, p. 785-790, jan./fev. 2007.

CETESB. Companhia Ambiental do Estado de São Paulo. Aterro Sanitário: Disponível em: http:// www.cetesb.sp.gov.br/mudancas-climaticas/biogas/ Aterro\%20Sanit\%C3\%A1 rio/21 Aterro\%20Sanit\%C3\%A1rio. Acesso em: 29/03/2013.

FONTAINE, J.; DEWAILLY, E.; BENEDETTI, J-L.; PEREG, D.; AYOTTE, P.; DÉRY, S. Re-evaluation of blood mercury, lead and cadmium concentrations in the Inuit population of Nunavik (Québec): a cross-sectional study. Environmental Health, 2008.

GONÇALVES Jr., A. C.; LUCHESE, E. B.; LENZI, E. Avaliação da fito disponibilidade dos metais pesados tóxicos cádmio, chumbo e cromo, em soja cultivada num latossolo vermelho escuro, a partir de fertilizantes comerciais.. In: $22^{a}$ Reunião Anual da Sociedade Brasileira de Química, 1999, Poços de Caldas - MG. $22^{\text {a }}$ Reunião Anual da Sociedade Brasileira de Química. São Paulo: SBQ, 1999. v. AB.

HAN X. Y.; ZHUO, S. J.; SHEN, R. X.; WANG, P. L.; JI A. Comparison of the quantitative results corrected by fundamental parameter method and difference calibration specimens in $\mathrm{x}$-ray fluorescence spectrometry. Journal of Quantitative Spectroscopy and Radiative Transfer, v. 97, n. 1, p. 68-74, 2006.

IBGE. Instituto Brasileiro de Geografia e Estatística. Pesquisa Nacional de Saneamento Básico de 2000. São Paulo. Disponível em: http://www.ibge.gov.br/ home/. Acesso em: 12/02/2013. 
JIMENEZ, R. S.; DAL BOSCO, S. M.; CARVALHO, W. A.; Remoção de Metais Pesados de Efluentes Aquosos pela Zeólita Natural escolecita -influência da temperatura e do $\mathrm{pH}$ na adsorção em sistemas monoelementares. Quim. Nova, Vol. 27, No. 5, 734738, 2004.

KEMERICH, P. D. C.; UCKER, F. E.; BORBA, W. F. Cemitérios como Fonte de Contaminação Ambiental, Scientific American Brasil, São Paulo, n. 123, p 78-81, Agos. 2012.

Kemerich, P.D.C.; MARTINS, S. R.; KOBIYAMA, M.; SILVEIRA, R. L.; DESCOVI FILHO, L.; RIZZARDI, A. S.; BORBA, W. F. Vulnerabilidade Natural À Contaminação Da Água Subterrânea $\mathrm{Na}$ Bacia Hidrográfica Do Rio Vacacaí-Mirim: Uso Da Metodologia God. Engenharia Ambiental (Online), v. 10, p. 189-207, 2013.

KING, L. D. Retention of metals by several soils of the Southeastern United States. Journal Environmental Quality, Madison, v.17, p.239-246, 1988.

LANDIM, P. M. B.; STURARO, J. R. Krigagem indicativa aplicada à elaboração de mapas probabilísticos de riscos. Rio Claro: DGA,IGCE,UNESP: 253 p. 2002.

LAZARINI, H. Agravos à saúde de uma amostra populacional exposta ao risco ambiental nos bairros Soledade e Robalo, Aracaju-SE. Dissertação de Mestrado. Universidade Tiradentes, Programa de Pós-graduação em saúde e ambiente, 2011.

LEITE, C. M. B; BERNARDES, R. S. O.; SEBASTIÃO A. Método Walkley-Black na determinação da matéria orgânica em solos contaminados por chorume. Revista Brasileira de Engenharia Agrícola e Ambiental. 8: 111-5. 2004.

LINDSAY, W. Chemical equilibria in soils. New York, WileyInterscience, 1979. 449p. 1979.

LOGANATHAN, P. Effect of phosphate fertilizer type on the accumulation and plant availability of cadmium in grassland soils. Nutrient Cycling in Agroecosystem, Dordrecht, v.47, p.169-178, 1997.

MALAVOLTA, E. Elementos de Nutrição Mineral de Plantas. Editora Agronômica Ceres, São Paulo. 251 p. 1980.

MUÑOZ, S. I. S; Impacto Ambiental Na Área do Aterro Sanitário E Incinerador De Resíduos
Sólidos De Ribeirão Preto São Paulo. Programa de Pós Graduação de Enfermagem e Saúde Pública. Ribeirão Preto. 2002.

NASCENTES, R.; AZEVEDO, I. C. D.; MATOS, A. T.; AZEVEDO, R. F.; POSSSATO, E. L JESUS, S. C. Parâmetros de transporte do manganês e do zinco em solo residual compactado - método da massa acumulada, Revista Águas subterrâneas, São Paulo, 2009.

NASCIMENTO, S. C.; HYPOLITO, R.; RIBEIRO, A. A. Disponibilidade de Metais Pesados em Aterro de Indústria Siderúrgica. Vol.11 - No 3 - jul/ set, 196-202. 2006.

OLIVEIRA, M. J.; SOUTO, F. A. F.; ROSARIO, J. M. L.; SACASA, R. J. V.; MOURA, H. P. Vulnerabilidade Natural e Sazonalidade Do Aquífero Livre No Loteamento Marabaixo III - Macapá - AP. In: XIII Congresso Brasileiro de Águas Subterrâneas, 2004,

PAN, J.; PLANT, J. A.; VOULVOULIS, N.; OATES, C. J.; IHLENFELD, C. Cadmium levels in Europe: implications for human health. Environ Geochem Health, 32, p. 1-12, 2010.

PATACA, L. C.; BORTOLETO, G. G.; BUENO, M. I. M. S. Determinação de arsênio em águas contaminadas usando Fluorescência de raios-X por Energia Dispersiva. Revista Química Nova, São Paulo, v.28, no.4, p. 589-582. jul./agos. 2005.

PELOZATO, M.. Valores de referência de cádmio, cobre, manganês e zinco para solos de Santa Catarina. Lajes, UDESC. 70p. (Dissertação de Mestrado). 2008.

SANTOS, G. O.; MEDEIROS, P. A. Estudo preliminar da qualidade das águas subterrâneas na área de influência do aterro sanitário de Caucaia. Conexões: Ciência e Tecnologia, v. 5, p. 61-70, 2011.

SILVA, D. J.; DEON, M. D.; BASSOI, L. H.; SILVA, D. O. M.; SILVA, J. A. Alterações nas concentrações de cobre e manganês no solo em cultivo de videiras Syrah submetidas à adubação orgânica e fertirrigação nitrogenada. In: Fertbio, 2012, Maceió. Anais, 2012.

SILVA, F. N.; CHANG, A., FURTINE-NETO, A.; MAIA, S. S. S. Aplicação do modelo de balanço de massa para simulações dos teores de elementos-traço 
em solos do cerrado. Revista Caatinga, 23(2), p. 93-101, 2010.

TARTARI, L. C.. Avaliação do Processo de Tratamento do Chorume de Aterro Sanitário de Novo Hamburgo. Revista Liberato, v. 6, n. 6, p. 66-74, 2005.

WASTOWSKI A. D.; DA ROSA G. M.; CHERUBIN M. R.; RIGO J. P G. Caracterização dos Níveis de Elementos Químicos Em Solo, Submetido a Diferentes Sistemas de Uso E Manejo, Utilizando Espectrometria de Fluorescência de Raios-X Por Energia Dispersiva (EDXRF). Revista Química Nova, São Paulo, v.33, n.7, p. 1449-1452, mar./abr, 2010. 